\title{
Linking Fruit Ca Uptake Capacity to Fruit Growth and Pedicel Anatomy, a Cross-Species Study
}

\author{
Wenpei Song ${ }^{1}$, Junwen Yi ${ }^{1}$, Odit F. Kurniadinata ${ }^{2}$, Huicong Wang ${ }^{1}$ and Xuming Huang ${ }^{1 *}$ \\ ${ }^{1}$ College of Horticulture, South China Agricultural University, Guangzhou, China, ${ }^{2}$ Department of Agronomy and Horticulture, \\ Faculty of Agriculture, Bogor Agricultural University, Bogor, Indonesia
}

OPEN ACCESS

Edited by:

Victoria Fernandez, Universidad Politécnica de Madrid

(UPM), Spain

Reviewed by:

Jesus Val,

Consejo Superior de Investigaciones Cientificas (CSIC), Spain

Giuseppe Montanaro,

University of Basilicata, Italy

${ }^{*}$ Correspondence:

Xuming Huang

huangxm@scau.edu.cn

Specialty section: This article was submitted to Plant Nutrition,

a section of the journal

Frontiers in Plant Science

Received: 07 February 2018

Accepted: 13 April 2018

Published: 09 May 2018

Citation:

Song $W, Y i J$, Kurniadinata OF, Wang $H$ and Huang $X(2018)$ Linking

Fruit Ca Uptake Capacity to Fruit Growth and Pedicel Anatomy,

a Cross-Species Study.

Front. Plant Sci. 9:575.

doi: 10.3389/fpls.2018.00575
Calcium (Ca) in flesh fruits is important for quality formation and maintenance. Most studies on fruit Ca focus on one species. This study attempted to understand some universal relations to fruit $\mathrm{Ca}$ uptake across species. Calcium contents in fruit tissues were analyzed in different fruits, including three cultivars of litchi, two cultivars each of grape and citrus, and one cultivar each of loquat, apple, pear, Indian jujube, and longan. In situ Ca distribution was revealed with electron probe and xylem functionality visualized by dye tracing. Fruit $\mathrm{Ca}$ uptake rate and activity were calculated and correlated with fruit growth and pedicel anatomy. The results showed that fruit Ca uptake rate was the highest in pomes (loquat, apple, and pear), followed by Indian jujube drupe, arillate fruits (litchis and longan) and citrus, while grape berries were the lowest. Fruit Ca uptake rate showed a strong positive correlation to growth rate. However, Ca uptake activity, reflecting Ca uptake rate relative to growth, was the highest in arillate fruits and loquat and lowest in grape berries, and had a poor correlation with fruit growth rate. In all fruits, Ca concentration in the pedicel was higher than in the fruit, and they displayed a good positive correlation. In the pedicel, Ca was most abundant in the phloem. Dye tracing showed that xylem function loss occurred with maturation in all species/varieties. Apple had the poorest xylem functionality with the least development of secondary xylem, but its Ca uptake rate was among the highest. Vessel density, size and area in the pedicel showed no correlation with fruit Ca uptake rate. It is concluded that: (1) fruit growth may be a key determinant of Ca uptake; (2) the universal pattern of Ca being higher in the pedicel than in the fruit indicates existence of a pedicel-fruit "bottleneck" effect in Ca transport across species; (3) xylem functionality loss with fruit maturation is also a universal event; (4) in the pedicel, Ca is more distributed in the phloem; (5) vessel morphology in the pedicel is not rate-limiting for fruit Ca uptake; (6) phloem pathway might contribute to fruit Ca uptake.

\footnotetext{
Keywords: calcium transport pathway, calcium uptake rate, calcium uptake activity, xylem functionality, vessel characters, fruit growth
}

\section{INTRODUCTION}

In plant, calcium $(\mathrm{Ca})$ has irreplaceable functions such as construction of cell wall and signal transduction involving responses to external or internal signals (White and Broadley, 2003; Hocking et al., 2016). Studies have shown that systemic or localized Ca deficiency in plants causes various physiological disorders leading to substantial yield and quality losses (Shear, 1975; 
Huang et al., 2005a; Saure, 2005; Yang and Jie, 2005; Tonetto de Freitas and Mitcham, 2012). Fruit, a terminal organ with low transpiration, is more vulnerable to shortage of Ca supply (White and Broadley, 2003). However, development of Ca deficiency symptoms is determined by a number of internal and external factors including transport of $\mathrm{Ca}$ to fruit, $\mathrm{Ca}$ allocation and subcellular distribution (Bangerth, 1979; Ho and White, 2005; Tonetto de Freitas et al., 2014; Hocking et al., 2016).

Fruits are architecturally isolated organs connected to tree by pedicel/peduncle, where sap carrying various nutrients is fed to fruit via xylem and phloem. The transport of $\mathrm{Ca}$ to fruit in the pedicel does not seem smooth, as our studies showed that $\mathrm{Ca}$ concentration in the pedicel/peduncle was 10 times higher than in fruit in litchi, reminiscent of a "bottleneck effect" in Ca transport to the fruit (Huang et al., 2006; Song et al., 2018). If such bottleneck effect exists, then the more $\mathrm{Ca}$ moves into fruit, the more $\mathrm{Ca}$ is sequestered in the pedicel, and a positive correlation between fruit $\mathrm{Ca}$ uptake and $\mathrm{Ca}$ concentration in the pedicel will thus be expected. We are interested to examine the pedicel-fruit $\mathrm{Ca}$ gradient in a wider range of fruit types and analyze the correlation between fruit $\mathrm{Ca}$ uptake and $\mathrm{Ca}$ sequestration in the pedicel.

Although it is generally believed that $\mathrm{Ca}$ transport is exclusively through the xylem/apoplast pathway (Ferguson, 1980; Hanson, 1984; Zocchi and Mignani, 1995; Saure, 2005; Hocking et al., 2016), there are some studies showing that phloem can be an important pathway for Ca delivery (Stebbins and Dewey, 1972; Himelrick and McDuffie, 1983; Vemmos, 2005; Song et al., 2018). We recently found Ca content in the phloem was much higher than in the xylem in litchi pedicel, indicative of possible Ca deliver to fruit via phloem mass flow (Song et al., 2018). It is not known whether this Ca distribution pattern in the pedicel is universal in different fruit species.

The xylem-based $\mathrm{Ca}$ transport is influenced by factors including the rate of xylem sap inflow, the competition between ions for binding sites in xylem vessel walls and pit membranes, and sequestration by organic acids like oxalate (Franceschi and Nakata, 2005; Saure, 2005; Gilliham et al., 2011; Hocking et al., 2016). The xylem inflow resulting from fruit transpiration and fruit growth is a key determinant for fruit to acquire $\mathrm{Ca}$ (Montanaro et al., 2014, 2015; Tonetto de Freitas et al., 2014. Fruit transpiration is a function of vapor pressure deficit (VPD) (Montanaro et al., 2012). Montanaro et al. (2015) showed that fruit Ca gain in kiwifruit is coupled to transpiration at high VPD that induces high fruit transpiration, while at low VPD with low fruit transpiration, fruit growth dominates Ca uptake. Xylem inflow rate is also a function of hydraulic conductivity, which is determined by xylem functionality and positively related to vessel diameter and frequency. In fruits like apple (Miqueloto et al., 2014), grape (Coombe and McCarthy, 2000; Choat et al., 2009) and kiwi (Dichio et al., 2003), loss of xylem functionality occurs during fruit development, especially in late stages. In apple, time of xylem functionality loss is related to susceptibility to bitter pit, a disorder caused by Ca deficiency (Miqueloto et al., 2014). Xylem conductivity is also determined by xylem anatomic features in the pedicel, which theoretically have an impact on fruit Ca uptake. However, there is a lack of study exploring this impact.

Previous studies of fruit Ca focused on one species. Different cultivars of the same species, apple (Miqueloto et al., 2014) and litchi (Huang et al., 2006) for example, show great difference in fruit $\mathrm{Ca}$ uptake and thus in susceptibility to disorders caused by Ca deficiency. Therefore, genetic background is a key determinant of fruit Ca uptake capacity. However, there is little information about fruit attributes related to the difference in Ca uptake capacity cross species. In this study, a cross-species analysis of fruit $\mathrm{Ca}$ uptake capacity was carried out in relation to pedicel anatomy and xylem functionality as well as to fruit growth rate in order to generalize some universal relations to fruit $\mathrm{Ca}$ uptake capacity across fruit species.

\section{MATERIALS AND METHODS}

\section{Materials}

Twelve varieties of 8 fruit species, including 3 cultivars of litchi, 2 cultivars each of grape and citrus, and 1 cultivar each of loquat, apple, pear, jujube, and longan, were chosen as the experimental materials for this study. Information of the fruits and their abbreviated codes are listed in Table 1. Mature fruit with stalk of each variety were harvested from at least 3 trees on the dates shown in Table 1. For convenience, the codes of the materials are used in the following text. Apple (MdTM1) and pear (Pp-WK) samples were collected from the experimental orchard of the Horticultural Institute, Guizhou Academy of Agricultural Sciences (Guizhou, China) with a soil $\mathrm{pH}$ of 6.83 and available $\mathrm{Ca}$ around $680 \mathrm{mg} \mathrm{kg}^{-1}$; citrus $(\mathrm{Cr}-$ STJ and Cr-MSJ), loquat (Ej-ZZ6) and grape ( $\mathrm{Vv-SB}$ and $\mathrm{Vv}-\mathrm{SM})$ samples were taken from the experimental orchard of South China Agricultural University (Guangzhou, China) with a soil $\mathrm{pH}$ of 5.47 and available $\mathrm{Ca}$ around $320 \mathrm{mg} \mathrm{kg}^{-1}$; litchis (LcLFN, Lc-GW, and Lc NMC) and longan (Dl-SX) were sampled from Xili Orchard (Shenzhen, China) with a soil $\mathrm{pH}$ of 5.1 and available $\mathrm{Ca}$ around $250 \mathrm{mg} \mathrm{kg}{ }^{-1}$; Indian Jujube (ZmDMS) fruit were from the experimental orchard of Tropical and Subtropical Crop Institute, China Academy of Tropical Horticultural Sciences (Zhanjiang, China) with a soil pH of 5.4 and available $\mathrm{Ca}$ around $400 \mathrm{mg} \mathrm{kg}^{-1}$. Changes VPD in different sites during fruit development are shown in Supplementary Figures S1, S2. The average VPDs throughout the period of fruit development of all the tested fruits are also shown in Table 1 .

\section{Determination of Calcium Uptake Capacity of Fruit}

Ten mature fruit with stalk were harvested from each of selected trees. The fruit were individually separated into stalk, skin, flesh, and seed and their fresh weights were collected before oven dried at $65^{\circ} \mathrm{C}$ for $72 \mathrm{~h}$. After the dry weight of each part was recorded, the dried samples were ashed in a muffle furnace. The ashed samples were separately dissolved in $0.1 \mathrm{~mol} \mathrm{~L}^{-1} \mathrm{HCl}$ solution, and $\mathrm{Ca}$ content was analyzed using a flame atomic absorption spectrophotometer (Z-2300, 
TABLE 1 | Information of the experimental materials used in this study.

\begin{tabular}{|c|c|c|c|c|c|}
\hline Materials & Code & Tree information & Flowering date & Sampling Date & $\begin{array}{l}\text { Average VPD during } \\
\text { fruit growth (kPa) }\end{array}$ \\
\hline Malus domestica cv. Tengmu No.1 & Md-TM1 & $\begin{array}{l}\text { 8-year-old trees grafted on Malus } \\
\text { spectabilis }\end{array}$ & May 1, 2015 & July 5, 2015 & 0.696 \\
\hline Pyrus pyrifolia. cv. Whangkeumbae & Pp-WK & $\begin{array}{l}\text { 8-year-old trees grafted on Pyrus } \\
\text { betulifolia }\end{array}$ & May 1, 2015 & July 31, 2015 & 0.765 \\
\hline Citrus reticulate cv. Shatangju & Cr-STJ & $\begin{array}{l}\text { 8-year-old trees grafted on } \\
\text { Poncirus trifoliata }\end{array}$ & April 10, 2015 & December 26, 2015 & 0.548 \\
\hline Citrus reticulate cv. Mashuiju & Cr-MSJ & $\begin{array}{l}\text { 8-year-old trees grafted on } \\
\text { Poncirus trifoliata }\end{array}$ & April 10, 2015 & November 24, 2015 & 0.545 \\
\hline Eriobotrya japonica cv. Zaozhong No.6 & Ej-ZZ6 & 16-year-old self-rooted trees & November 27, 2015 & March 17, 2016 & 0.557 \\
\hline Vitis vinifera cv. Summer black & $V_{V}-S B$ & 3-year-old vines on Beta rootstock & April 1, 2015 & June 27, 2015 & 0.390 \\
\hline Vitis vinifera cv. Shine Muscat & Vv-SM & 3-year-old vines on Beta rootstock & April 1, 2015 & July 10, 2015 & 0.451 \\
\hline Litchi chinensis cv. Lingfengnuo & Lc-LFN & $\begin{array}{l}\text { 4-year-old branches top-grafted on } \\
\text { Huaizhi }\end{array}$ & April 8, 2016 & June 23, 2016 & 0.395 \\
\hline Litchi chinensis cv. Guiwei & Lc-GW & 18-year-old trees grafted on Huaizhi & April 7, 2016 & June 26, 2016 & 0.395 \\
\hline Litchi chinensis cv Nuomici & LC-NMC & 18-year-old trees grafted on Huaizhi & April 7, 2016 & June 26, 2016 & 0.395 \\
\hline Dimocarpus longan cv. Shixia & DI-SX & $\begin{array}{l}\text { 18-year-old trees grafted on } \\
\text { Chuliang }\end{array}$ & April 15, 2016 & July 31, 2016 & 0.480 \\
\hline Ziziphus mauritiana cv. Damisi & Zm-DMS & $\begin{array}{l}\text { 13-year-old trees grafted on } \\
\text { Yuenanzao }\end{array}$ & September 26, 2016 & December 25, 2016 & 0.853 \\
\hline
\end{tabular}

Hitachi, Japan). After Ca content in each fruit part was collected, total content of calcium in individual fruit was calculated by summing the Ca contents in seed, flesh and skin. This was further used to calculate fruit Ca uptake rate and fruit Ca uptake activity.

Fruit Ca uptake rate $\left(\mu \mathrm{g} \mathrm{d}^{-1}\right)=$ Total fruit Ca content/days of fruit development (from anthesis to harvest).

The fruit Ca uptake rate thus calculated refers to the average Ca accumulation per day per fruit during the whole period of fruit development.

Fruit calcium uptake activity $\left(\mu \mathrm{g} \mathrm{d}^{-1} \mathrm{~g}^{-1} \mathrm{DW}\right)=$ Fruit uptake rate/fruit dry weight.

Fruit Ca uptake activity reflects Ca uptake rate relative to fruit biomass accumulation and thus shows the balance between fruit Ca uptake and fruit growth.

\section{Xylem Functionality Observation Using Dye Tracing}

Five fruit with stalks of each species/variety were randomly collected from the trees at full maturity as well as at the early maturing phase, when fruits shifted from a utilization sink to a storage sink and started to accumulate assimilates. The exact sampling times (days after full bloom, DAFB) can be found in Table 2. Fruit samples were fed with $1 \%(\mathrm{w} / \mathrm{v})$ safranin $\mathrm{O}$ solution via fruit stalk by submerging the freshly cut stalk end into the solution. Twenty four hour later, the fruit were cut into equal halves longitudinally from fruit top to fruit base. Distribution of the red dye reflecting functionality of xylem in fruit/pedicel was revealed and photographed.

\section{In Situ Ca Distribution in Pedicel Tissues}

The structure of and $\mathrm{Ca}$ distribution in fruit pedicel were observed with a JXA -8100 electron probe microanalyzer.
TABLE 2 | Times of sampling for vessel functionality observations.

\begin{tabular}{lll}
\hline Materials (common species name) & Early maturing phase & Ripe phase \\
\hline Ej-ZZ6 (loquat) & DAFB 90 & DAFB 110 \\
Md-TM1 (apple) & DAFB 53 & DAFB 65 \\
Pp-WK (pear) & DAFB 49 & DAFB 91 \\
Cr-STJ (citrus) & DAFB180 & DAFB 260 \\
Vv-SB (grape) & DAFB 51 \\
Vv-SM (grape) & DAFB 51 \\
DI-SX (longan) & DAFB 72 \\
LC-GW (litchi) & DAFB 63 88 \\
LC-NMC (litchi) & DAFB 63 & DAFB 101 \\
Zm-DMS (Indian Jujube) & DAFB 60 & DAFB 80 \\
\hline
\end{tabular}

Sample preparation, observation and image processing were carried out according to Song et al. (2014). The pedicels were cut into $0.2 \mathrm{~mm}$ thick cross sections, stuck onto a cupper sample stand with electricity-conductive carbon glue, and coated with platinum in a JFC-1600 vacuum auto-coater for 90 s. During electron probe analysis, the working distance of all samples was set at $11 \mathrm{~mm}$, with a probe accelerating voltage of $20 \mathrm{KV}$ and an exciting current of $2 \times 10^{-8} \mathrm{~A}$. The panorama images of the pedicels of all fruits were collected at a magnification of 40 . Under a magnification of 150-300, secondary the electron images of the samples and the map images of Ca-characteristic X-ray signal (Ca mapping image) were separately collected. Intensity of Ca-characteristic X-ray signal which reflects $\mathrm{Ca}$ abundance was displayed by density of bright dots. Adobe Photoshop CS6 was used to extract the bright dot map and change it into red color. The calcium mapping image was combined with the corresponding secondary image to generate a direct view of in situ Ca distribution in the tissues. 


\section{Optical Microscopic Observation and Analysis of Pedicel Anatomy}

Pedicels from the above mentioned samples were collected, cut into $2 \mathrm{~mm}$ pieces and fixed in FAA solution (formalin: acetic acid: $70 \%$ alcohol $=1: 1: 9$ and $5 \mathrm{ml}$ glycerinum). After dehydration with gradient concentrations of alcohol solutions from 70 to $100 \%$ and cleared with butyl alcohol, the samples were embedded in paraffin. Sections of $10 \mu \mathrm{m}$ in thickness were cut with a rotary microtome (Leica, RM2235, Germany), and stained successively with safranin $(1 \mathrm{~g}$ in $100 \mathrm{ml}$ ) and fast green $(0.5 \mathrm{~g}$ in $100 \mathrm{ml}$ of $95 \%$ ethanol) after rehydration with gradient alcohol solutions from $100 \%$ to $70 \%$. The sections were observed and photographed under a ZEISS microscope equipped with AxioCam HRc Imager D2 (Germany). Vessel number in the cross sections of the pedicel was counted and the total cross area of the pedicel, the xylem area, and the vessel size were obtained with a Digimizer image analyzing software system. Three biological replicates in each fruit species/variety were used for this experiment.

\section{Statistical Analysis}

Fruit weight and Calcium contents in various fruit tissues were collected from at least 30 individual fruit. The results are presented as means $\pm \mathrm{SE}$. Analyses of variation (ANOVA), Scheffe multiple range tests and correlation analyses were carried out using the statistical package of SPSS 21 (SPSS Inc., Chicago, IL, United States).

\section{RESULTS AND ANALYSIS}

\section{Ca Uptake Capacity in Different Fruit Species/Varieties}

Table 3 shows fruit development duration and fruit size differed greatly among varieties/species. With the two parameters, the average fruit growth rate throughout fruit growth period can be calculated by dividing fruit weight with duration of fruit development. Pp-WK, Md-TM1 and Zm-DMS had the highest growth rate, while grape berries ( $\mathrm{Vv}$-SB and $\mathrm{Vv}-\mathrm{SM})$ and Dl-SX had the lowest. Fruit Ca concentration had significant difference among the tested fruit species/varieties. The fruits could be arbitrarily divided into three groups based on Ca concentration. The low Ca fruits with Ca concentration lower than $1 \mathrm{mg} \mathrm{g}^{-1} \mathrm{DW}$ included the two grape varieties( $\mathrm{Vv}$-SB and $\mathrm{Vv}-\mathrm{SM})$, Lc-NMC, Zm-DMS, Md-TM1, and Pp-WK; the medium Ca fruits with $\mathrm{Ca}$ concentration between 1 and $2 \mathrm{mg} \mathrm{g}^{-1}$ DW included Lc-LFN, Lc-GW and Ej-ZZ6; the high Ca fruits with calcium higher than $2 \mathrm{mg} \mathrm{g}^{-1}$ DW included the two citrus varieties (Cr-ST) and Cr-MSJ) and Dl-SX. In the flesh tissue, the edible part of fruit, Ca concentration was the highest in Ej-ZZ6, followed in descending order by Cr-MSJ, Cr-STJ, Zm-DMS, Md-TM1, Pp-WK, Dl-SX, Vv-SM, and Vv-SB, and litchis had the lowest $\mathrm{Ca}$ concentration in the flesh. Therefore, loquat and citrus fruits are good source of Ca nutrition for human beings. There was no defined pattern in fruit and flesh $\mathrm{Ca}$ concentrations among fruit types (e.g., drupes, pomes, berries, and arillate fruits).
$\mathrm{Ca}$ content per fruit is determined by fruit $\mathrm{Ca}$ concentration and fruit size. It was the highest in Cr-STJ and Cr-MSJ, EjZZ6, and Pp-WK, but lowest in the two grapes. Fruit Ca uptake rate showed a slightly different pattern, where pomes Ej-ZZ6, Md-TM1, and Pp-WK were among the highest, followed in descending order by Zm-DMS drupe, arillate fruits (litchis and DL-SX) and citrus, while the two grape berries were the lowest $\mathrm{Ca}$ uptake rate. Across different fruit species/varieties, fruit growth rate and Ca uptake rate displayed a significant positive correlation (Figure 1A).

Fruit $\mathrm{Ca}$ uptake activity displayed a quiet different picture from fruit Ca uptake rate (Table 3). Dl-SX fruit had the highest Ca uptake activity, followed by litchis (Lc-GW, Lc-LFN, and Lc-NMC), Ej-ZZ6, Md-TM1, the citrus varieties and Zm-DMS. Grape berries had the lowest Ca uptake activity. It seemed that arillate fruits (litchis and longan) had a relatively high Ca uptake activity. Within the species of litchi, Lc-GW fruit had the highest Ca uptake activity, while Lc-NMC the lowest. Fruit Ca uptake activity had no significant correlation with fruit growth rate (Figure 1B).

\section{Ca in the Pedicel and Its Relation to Fruit Ca}

It's worth noting that $\mathrm{Ca}$ concentrations in the pedicel were 3-10 folds higher than those in the fruit in all the tested species/varieties. The results suggested that during the process of $\mathrm{Ca}$ transport toward the fruit some of the $\mathrm{Ca}$ was sequestered in the pedicel. The correlation between Ca concentrations in the fruit and in the pedicel differed among fruit varieties (Table 3).

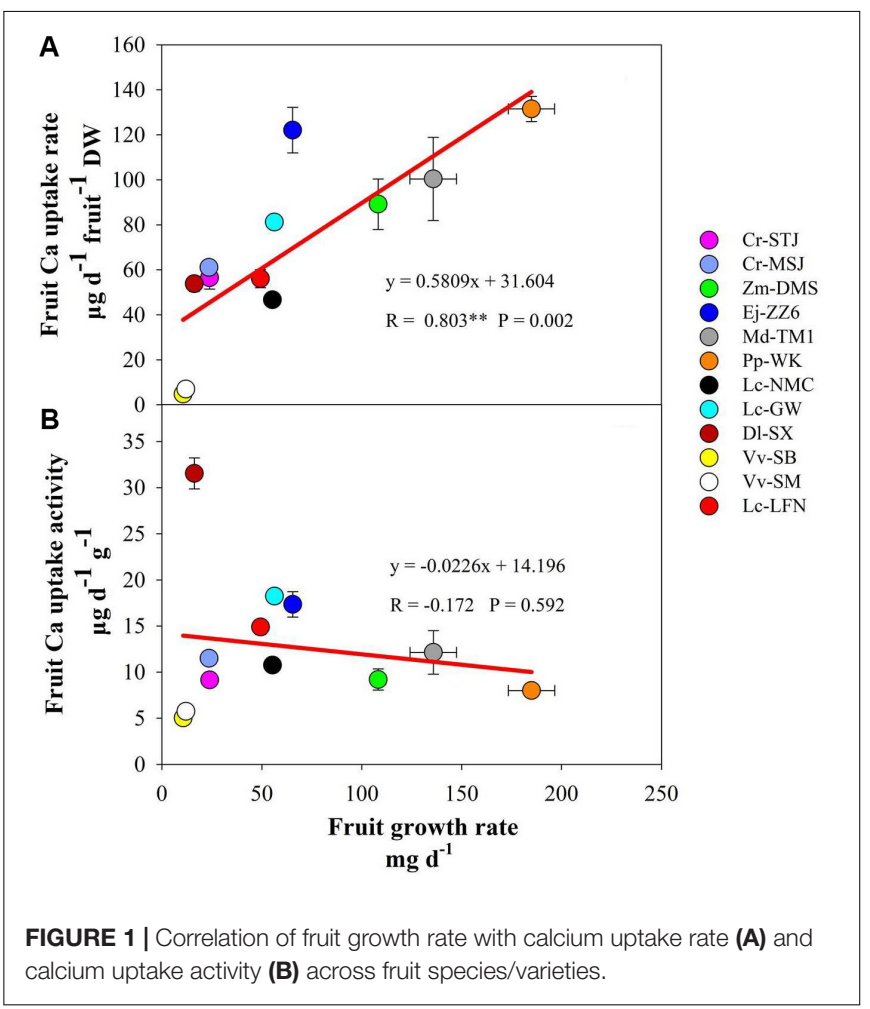




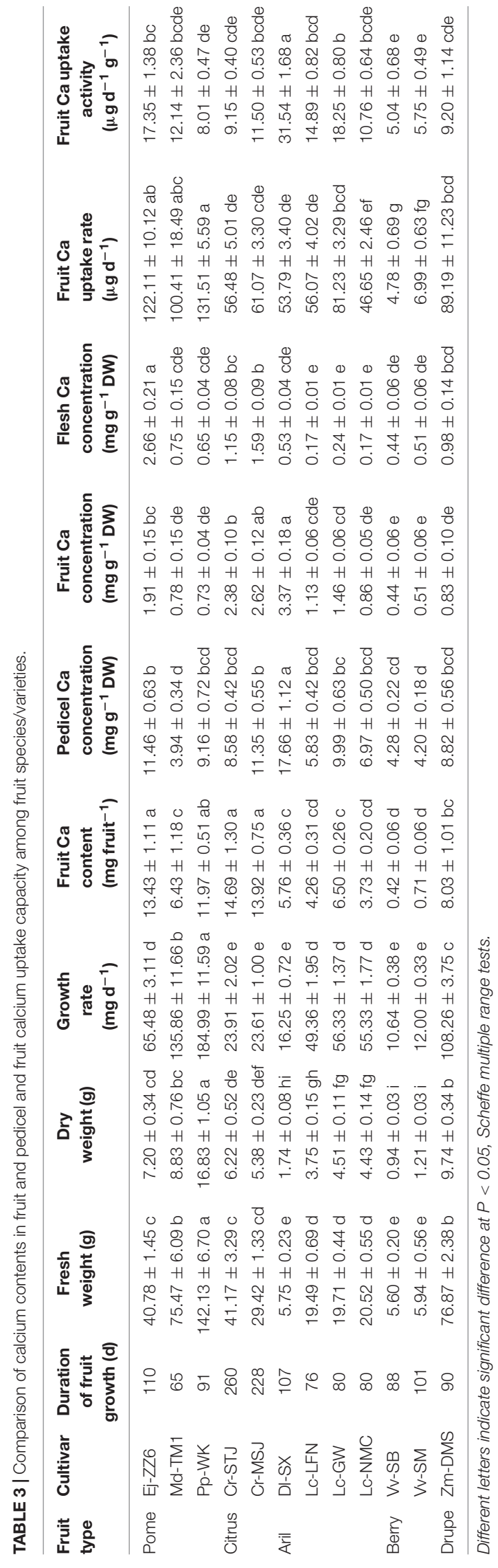

A significant positive correlation between Ca concentrations in the two parts was found in Dl-SX, Lc-GW, Lc-NMC, and EjZZ6 (Table 4). The correlation was weak and non-significant in the other species. However, across the species/varieties, Ca concentrations in the pedicel and in the fruit had a strong and significant positive correlation (Figure 2), suggesting a generally synchronous accumulation of $\mathrm{Ca}$ in the fruit and in the pedicel.

\section{Pedicel Morphology and Ca Distribution}

We used a scanning electron microscope equipped with an X-ray microanalyzer to visualize Ca distribution in the pedicel. Merging the secondary electron image and Ca mapping image shows in situ Ca distribution in various pedicel tissues (Figure 3). Anatomical characters of the pedicel are also shown in Figure 4. The pedicel of Zm-DMS had the smallest diameter while that of the Ej-ZZ6 was the largest among all the examined fruit species/varieties (Figure 3). The pedicel consisted of the pith at the very center, the vascular bundle chiefly composed of the xylem and phloem, the cortex, and the outermost epidermis ( $\mathrm{Zm}$ DMS and grapes) or periderm (other fruits examined) (Figure 4). The vascular bundles in the pedicel of most fruit species were ring-shaped, but those of the Md-TM1 and Pp-WK were clubshaped and scattered. Since, xylem is generally considered as the chief pathway for Ca transport, we focused on xylem characters. Xylem coverage, vessel number, vessel size and total vessel area in the cross sections of the pedicels are listed in Table 5. Both SEM and optical microscopic observations showed that apple (Md-TM1) had a poorly developed xylem with the lowest xylem coverage (12.46\%). The pedicel of the two citrus cultivars, $\mathrm{Cr}-$ STJ and Cr-MSJ had the highest xylem coverage of over $40 \%$. The 3 cultivars of litchis, Lc-NMC, Lc-LFN and Lc-GW, had similar xylem coverage in the range of $32.74-36.54 \%$, while its close relative, longan (Dl-SX) had much smaller xylem coverage (19.00\%). Similar to Md-TM1, Pp-WK had scattered vascular bundles, but it had higher xylem coverage (17.3\%). Zm-DMS and $\mathrm{Vv}-\mathrm{SB}$ had similar xylem coverage around $25 \%$. Vessel size and number differed among the fruit varieties. The 3 litchis, Cr-MSJ and Zm-DMS had the largest vessel size, while Dl-SX, Cr-STJ and Vv-SB had the smallest vessel size. The highest vessel number was found in Lc-NMC, followed by Dl-SX and the two citrus cultivars. Md-TM1 and Zm-DMS had the lowest vessel number. The total vessel area in cross section of pedicel was the highest in Cr-MSJ and Lc-NMC, followed by the other two cultivars of litchi, while the other fruits varied around 0.02$0.03 \mathrm{~mm}^{2}$.

Ca mapping with electron probe showed that $\mathrm{Ca}$ was not evenly distributed across the pedicel. In all the tested fruit species/varieties, Ca was more distributed in the phloem tissue than in the xylem tissue. Ca was most abundant in the phloem cells adjacent to the xylem (cambium). There were a lot of "Ca particles" scattered in the phloem, possibly corresponding to cells containing $\mathrm{Ca}$ oxalate. The results suggested flux of $\mathrm{Ca}$ to the phloem from the xylem during the process of $\mathrm{Ca}$ transport in the pedicel. Apparently, Dl-SX and Lc-GW had denser Ca particles in the phloem than the other fruit species/varieties examined. 
TABLE 4 | The correlations between calcium concentrations in the pedicel and the fruit in different species/varieties.

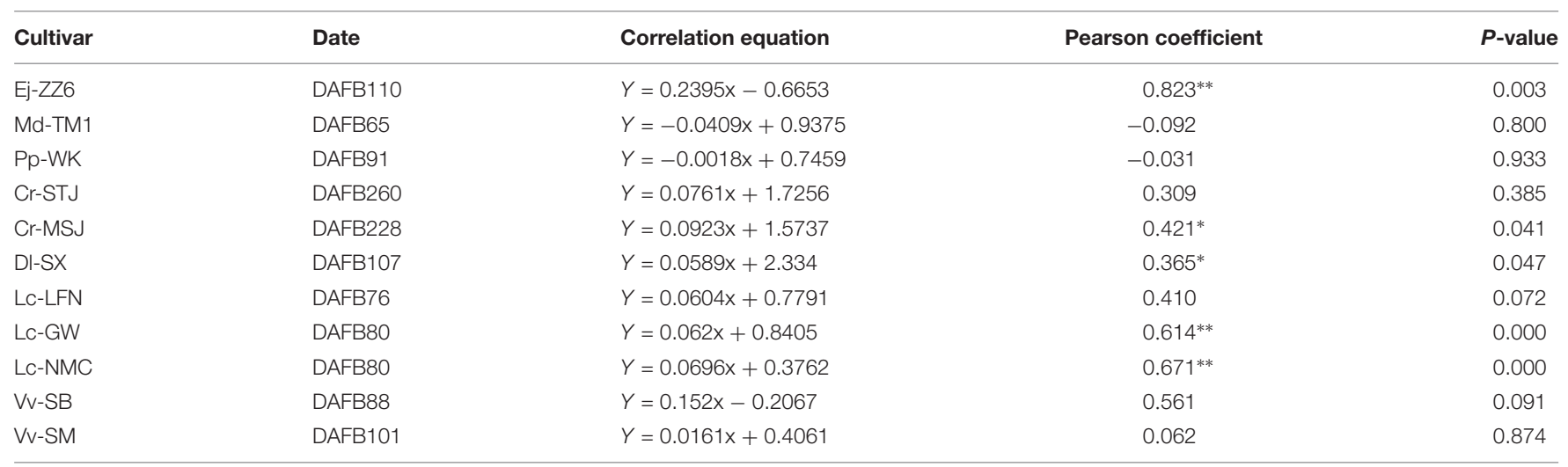

* and ** indicate significant correlation at $P<0.05$ and $P<0.01$, respectively.

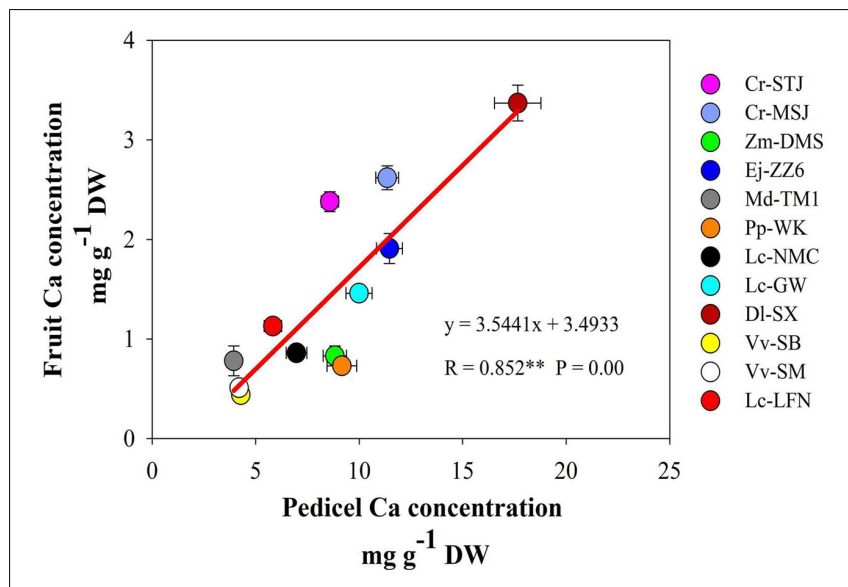

FIGURE 2 | The correlation between calcium concentrations in the pedicel and in the fruit across fruit species/varieties.

\section{Xylem Functionality Observation}

The continuity or functionality the xylem vessels was analyzed by using $1 \% \mathrm{w} / \mathrm{v}$ safranin $\mathrm{O}$ dye tracing. The results (Figure 5) showed that dye solution fed through fruit stalk had a greater coverage in the fruit tissues at the early maturing stage than at the ripe stage in all species/varieties examined. In ripe fruits of most species, the dye transport to the fruit was halted at the joining site of the fruit and the pedicel, indicating the site of vessel function loss. The results suggest that it is a general phenomenon that fruit xylem vessel gradually lose function with fruit maturation. Among the fruits examined, the pome of apple (Md-TM1) had the poorest vessel functionality, as no dye fed from the stalk could be observed in the fruit tissues even at the early maturing stage. The poor distribution of dye agreed with the poor development of xylem shown in Figures 3, 4. The result also suggested that fruit vessel function loss occurred earlier in Md-TM1 than the other species/varieties and that apple fruit might be a phloem-fed fruit during maturation. Two other pomes, Pp-WK and Ej-ZZ6, had a much better vessel functionality than apple, and the dye fed through the fruit stalk was relatively evenly distributed in their flesh tissue at the early maturing stage. In citrus and the arillate fruits of litchi and longan, dye could not enter the flesh tissue, where there was no vascular bundle, but was extensively distributed in the skin tissue with abundant vascular bundles. In the stone fruit of $\mathrm{Zm}$-DMS, the dye in the early maturing fruit was found in tissues around the stone, with less distribution in the outer flesh parts, while in ripe fruit, no dye was transported into the fruit, indicating a complete "cut-off" of the vessel system at the fruit base.

\section{Relations of Pedicel Xylem Parameters to Fruit Ca Uptake Capacity}

Across the fruit species/varieties, neither fruit $\mathrm{Ca}$ uptake rate nor fruit Ca uptake activity had a significant correlation with xylem area, xylem coverage, vessel number, vessel size or the total vessel area in the cross section of the pedicel (Table 6). The results suggest that the xylem morphology in the pedicel does not seem to create a rate limiting effect on fruit Ca uptake.

\section{DISCUSSIONS}

\section{Difference in Ca Uptake Capacity Among Fruits}

In the present study, we examined fruit $\mathrm{Ca}$ uptake in 12 species/varieties. However, in order to collected fruits of different species, we needed to take samples from different orchards across regions with different soil and climate conditions and culture practices, which exert significant influence on fruit $\mathrm{Ca}$ uptake (Saure, 2005; Montanaro et al., 2014) and thus complicate the cross-species comparison. Despite that, we can still see some general patterns in fruit $\mathrm{Ca}$ uptake in different species/varieties from our results. Fruit species with larger fruit size (e.g., pomes) tended to have a higher Ca uptake rate than those with smaller fruit size (e.g., grape berries), and there was a strong positive correlation between fruit Ca uptake and fruit growth rates (Figure 1A). Tromp (1979) showed a positive correlation between fruit growth and $\mathrm{Ca}$ accumulation among individual fruit of apple and concluded that fruit growth was a key determinant of fruit Ca uptake. Our results support his 


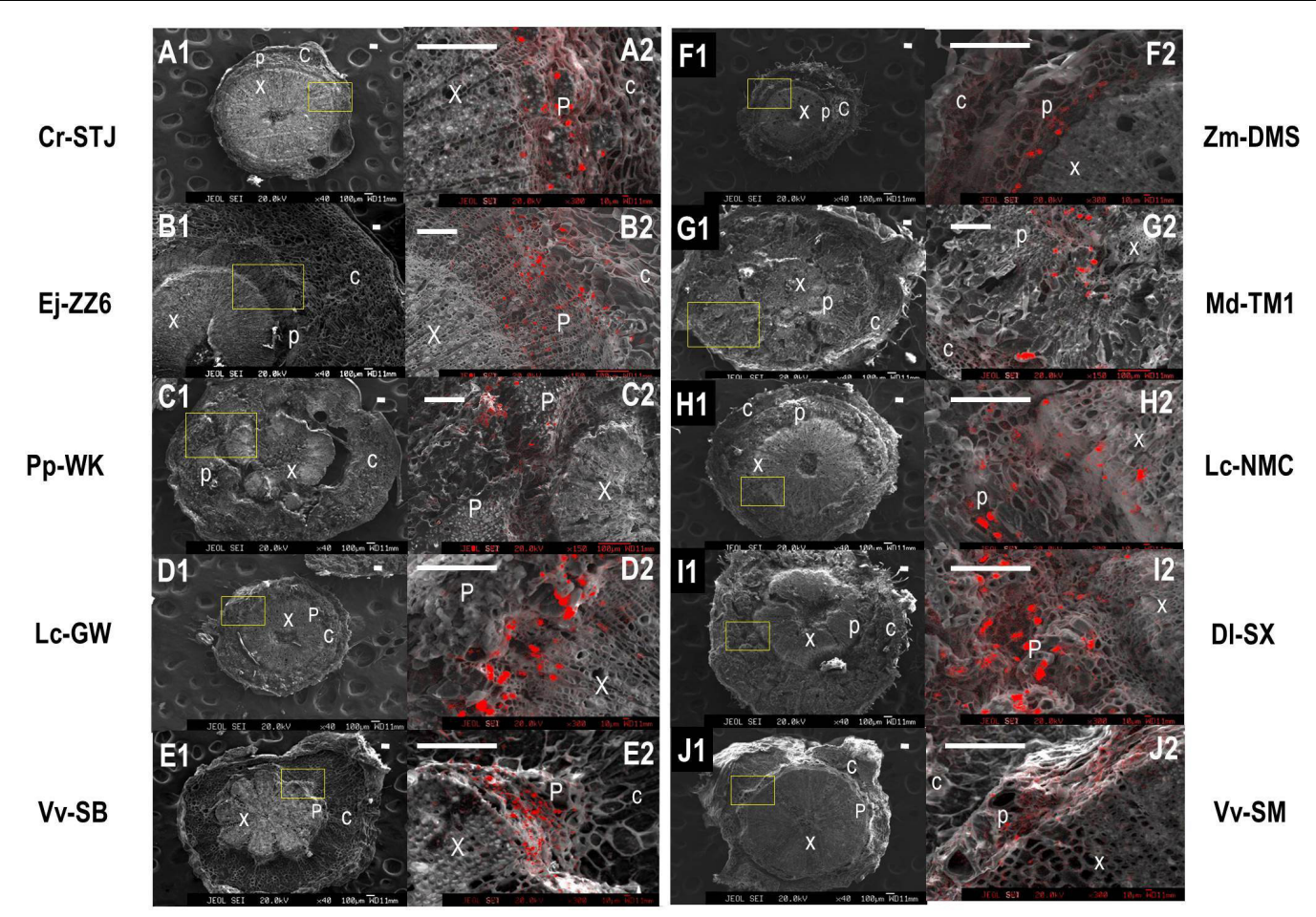

FIGURE 3 | The panorama secondary electron images of the pedicels and calcium distribution image in the magnified regions of the pedicels in different fruit species/varieties. (A1-J1) Are the panorama pedicel images of Cr-STJ, Ej-ZZ6, Pp-WK, Lc-GW, Vv-SB, Zm-DMS, Md-TM1, LC-NMC, DI-SX, and Vv-SM, respectively. (A2-J2) Are the calcium distribution images of the magnified areas corresponding to the squared part in the panorama images of the corresponding species/varieties. " $x$ " stands for xylem, "p" for phloem and "c" for cortex. Bars = $100 \mu \mathrm{m}$.

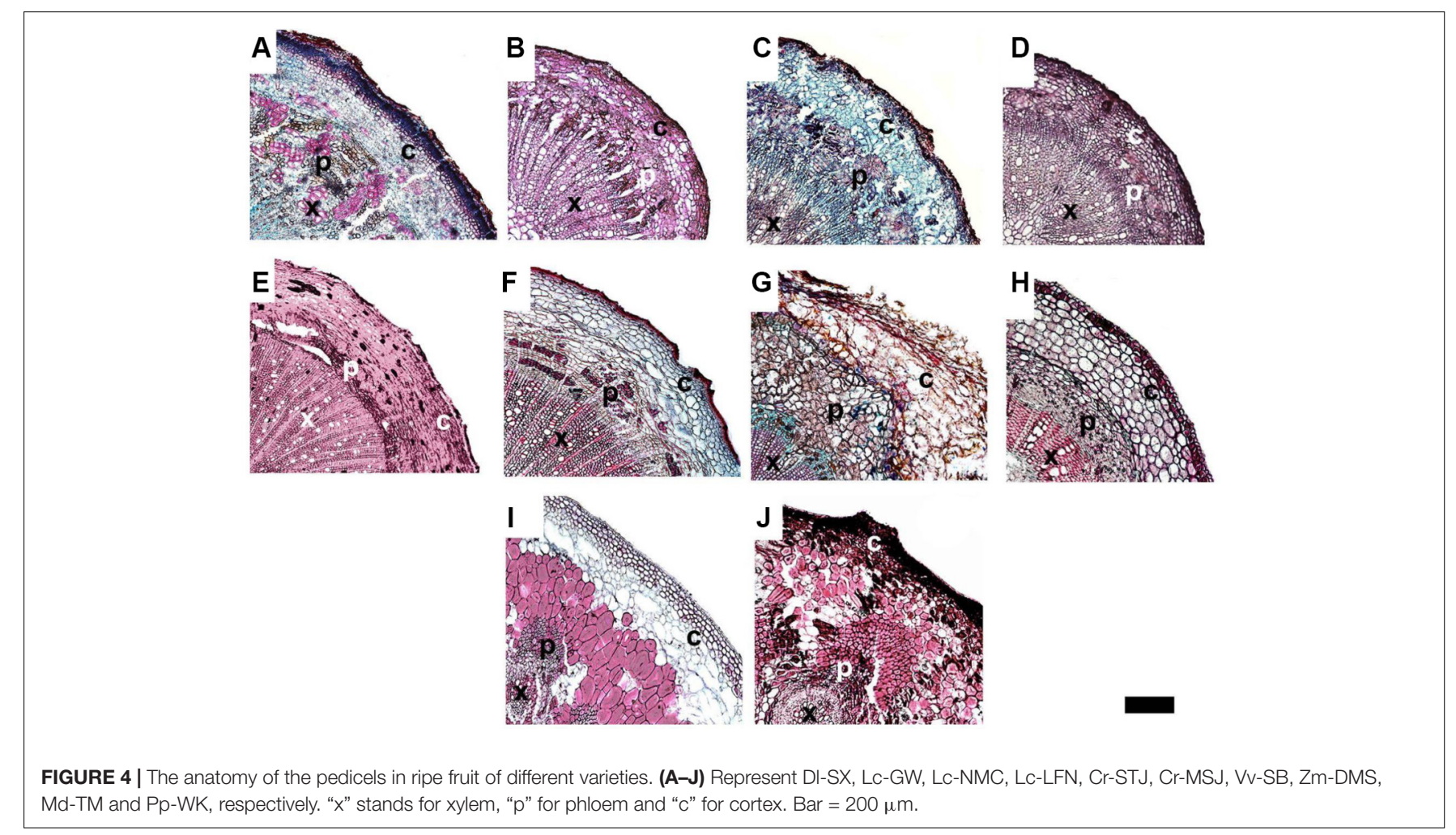




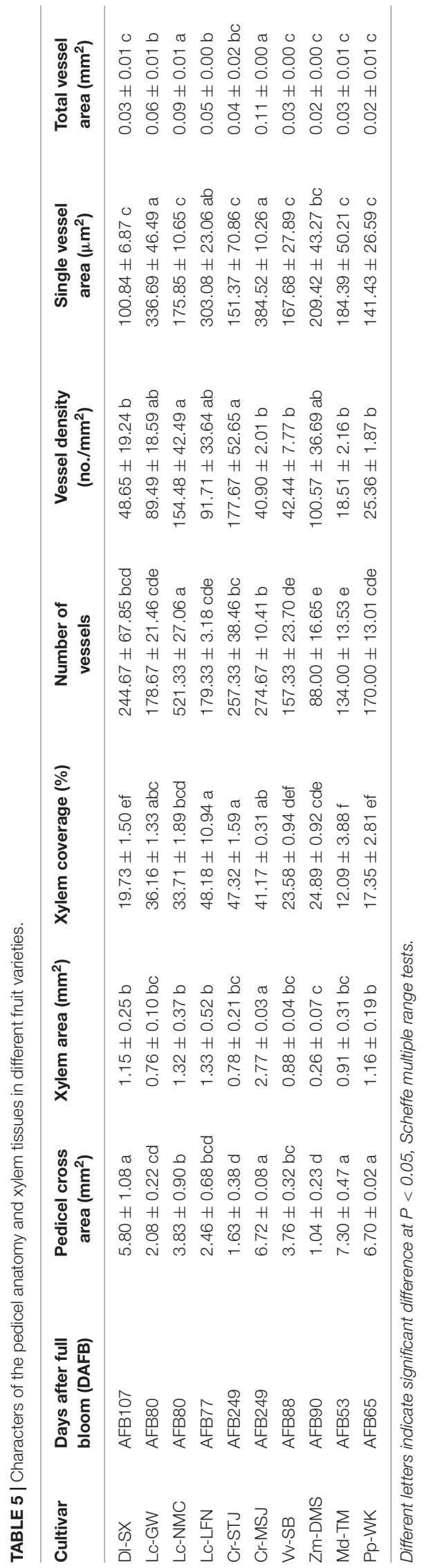

conclusion and suggested that this might be true across fruit species/varieties. VPD exerts a strong effect on fruit Ca gain, as it drives transpiration (Montanaro et al., 2010, 2015). In this study, the average VPDs during the development periods of all the tested fruits were all below $1.0(0.391-0.853)$ (Table 1). Montanaro et al. (2015) found that when VPD was very low, fruit $\mathrm{Ca}$ gain is more contributed by growth instead of transpiration. The close relation between $\mathrm{Ca}$ uptake and growth in fruit suggests fruit $\mathrm{Ca}$ uptake is largely demanddetermined.

Different cultivars of the same species (e.g., litchi, citrus and grape) had Ca uptake rates within a much narrower range compared with the cross-species range. However, significant difference in Ca uptake rate was found among different litchi cultivars (e.g., Lc-NMC vs. Lc-GW) grown in the same orchard under the same soil and climate conditions and culture practices. The results suggest that fruit Ca uptake capacity has a strong genetic background, which is the "behind-curtain" determinant of the permeance of fruit skin, the conductivity of $\mathrm{Ca}$ transport pathways as well as fruit size and growth rate.

However, during fruit development, rapid fruit expansion growth promoted by gibberellins, has been found associated with reduced $\mathrm{Ca}$ accumulation due to the suppression effect of gibberellins on Ca transport (Saure, 2005). Therefore, Ca deficiency frequently develops during vigorous growth. In this contest, Ca uptake rate relative to growth is a better index to show the balance between fruit Ca supply and the demand for growth. In this study, we adopted a novel parameter, fruit $\mathrm{Ca}$ uptake activity, $\mathrm{Ca}$ uptake rate per unit fruit mass, to reflect $\mathrm{Ca}$ uptake relative to growth (dry mass accumulation). The small arillate fruit of longan (Dl-SX) had a significantly higher fruit Ca uptake activity than the other species examined, while grapes had the lowest despite their smallest fruit size. Across species and varieties, fruit Ca uptake activity had no significant correlation with growth rate. Among the three litchi cultivars, Lc-GW and Lc-LFN had a higher Ca uptake activity than Lc-NMC (Table 3). The former two are less susceptible to fruit cracking and have a better postharvest performance than Lc-NMC (Fan et al., 2014; Huang et al., 2005a,b). Therefore, Ca uptake activity may be a good index to reflect the susceptibility to disorders associated with Ca deficiency in a given species.

As for Ca nutrition value of table fruits, flesh Ca concentration is more important than $\mathrm{Ca}$ content in the whole fruit, which contains non-edible tissues such as stones and leathery skin. Our study showed that loquat and citrus had the highest $\mathrm{Ca}$ content in the flesh and can be a good source for Ca nutrition. The $\mathrm{Ca}$ concentration in the flesh or aril of the litchis was the lowest. The results suggest that partitioning of imported $\mathrm{Ca}$ among fruit parts differs among fruit types.

\section{Xylem Functionality and Pathways of Ca Transport to Fruit}

Fruit is a terminal organ with almost all nutrients delivered from the tree through the connecting pedicel via xylem/apoplast pathway and/or phloem/ symplast pathway or both pathways. It 

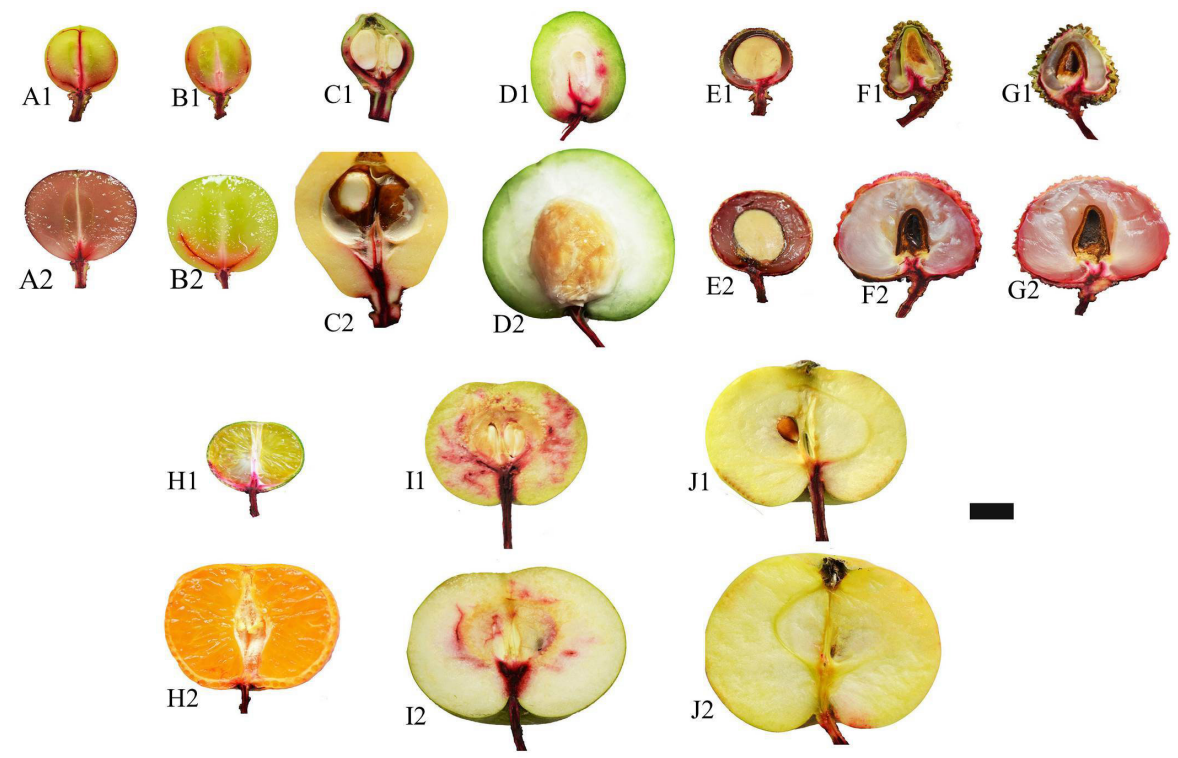

FIGURE 5 | Xylem functionality observations with dye tracing in different fruit species/varieties at early maturing stage and ripe stage. (A-J) Represent VV-SB, VV-SM, Zj-ZZ6, Zm-DMS, DI-SX, LC-NMC, LC-GW, Cr-STJ, Pp-WK, and Md-TM1, respectively, at early maturing stage when followed by 1 and at ripe stage by 2. $\operatorname{Bar}=1 \mathrm{~cm}$.

TABLE 6 | Cross-species correlations of xylem parameters with fruit calcium uptake capacity.

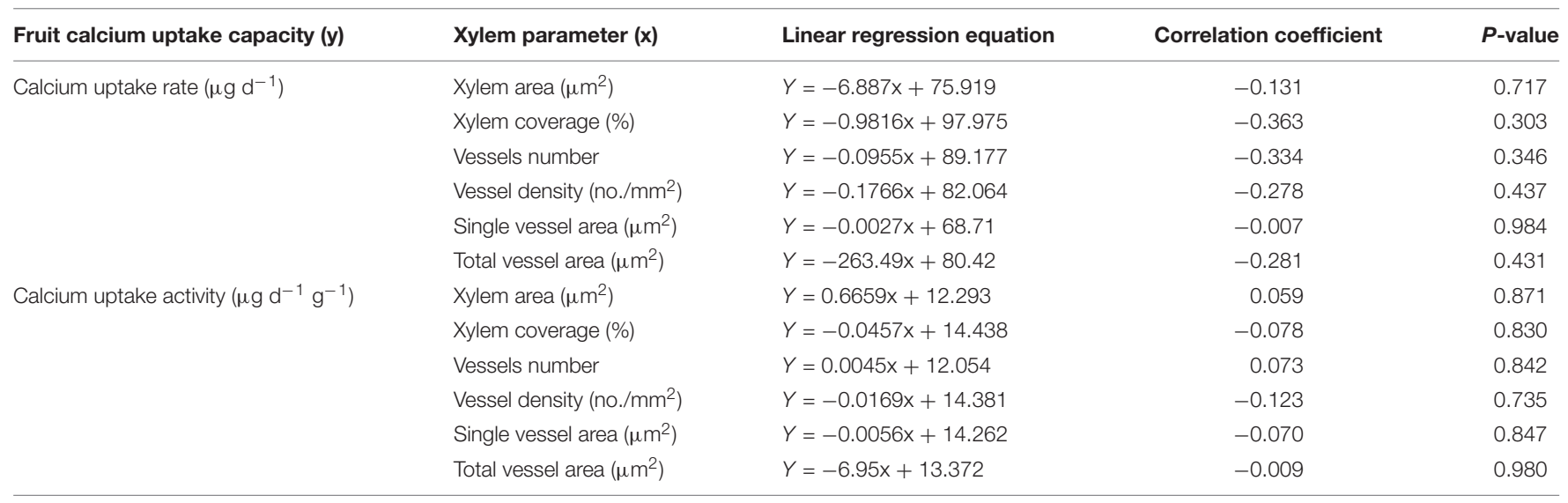

is generally accepted that $\mathrm{Ca}$ enters fruit exclusively through the xylem/apoplast pathway as $\mathrm{Ca}$ in phloem/symplast is maintained at a very low level (Saure, 2005; Tonetto de Freitas and Mitcham, 2012; Hocking et al., 2016). Therefore fruit Ca uptake is believed to be determined by Ca concentration in the xylem sap as well as xylem sap influx, which is related to fruit transpiration and growth (Montanaro et al., 2014; Hocking et al., 2016). Factors influencing xylem sap flow into the fruit, such as fruit transpiration (Montanaro et al., 2010, 2014) and xylem functionality (Dichio et al., 2003; Miqueloto et al., 2014), impact fruit Ca uptake. In many fruits, such as kiwi (Dichio et al., 2003), apple (Miqueloto et al., 2014) and grape berry (Düring et al., 1987; Coombe and McCarthy, 2000; Choat et al., 2009), vessel functionality showed dynamic changes due to balance between xylem functionality loss caused by vessel stretching during fruit expansion and vessel functionality recovery due to formation of new vessel, and at the late stage of fruit development, permanent loss of xylem functionality occurs. Time of vessel functionality loss in apple was found to differ according to cultivars, occurring at much earlier stage in 'Catarina' than in 'Fuji,' which explains the high susceptibility to bitter pit disorder in 'Catarina' (Miqueloto et al., 2014). The dynamics of vessel functionality has been shown to satisfactorily explain fruit Ca accumulation pattern (Dichio et al., 2003; Mazzeo et al., 2013; Miqueloto et al., 2014). Results in this study show that xylem functionality loss with fruit ripening is a universal phenomenon and that the site of xylem functionality loss is at the fruit-pedicel joint (Figure 5). Apple was shown to have weakest xylem functionality (Figure 4). In agreement with this, apple pedicel had the least development of vascular bundle among tested fruits (Figures 3, 4). However, xylem functionality difference among species/varieties could not satisfactorily explain 
the difference in fruit $\mathrm{Ca}$ capacity. For example, apple had the poorest vessel functionality and least development in the secondary xylem, but its fruit $\mathrm{Ca}$ uptake rate was among the highest. Jones et al. (1983) estimated the Ca accumulation in apple fruit based on vessel influx volume and $\mathrm{Ca}$ concentration and found great discrepancy between the estimated value and measured $\mathrm{Ca}$ accumulation. One of the explanations to this discrepancy was that phloem might also be a major pathway for Ca transport (Jones et al., 1983). There are studies showing that both the xylem and phloem participated in Ca movement into fruit (Himelrick and McDuffie, 1983; Yang and Jie, 2005; Song et al., 2018). Himelrick and McDuffie (1983) suggested that $\mathrm{Ca}$ transport into fruit was likely via the phloem but movement of $\mathrm{Ca}$ inside fruit was through the xylem. Our previous study also provided evidences showing important contribution of phloem pathway to fruit Ca uptake in litchi Song et al. (2018). Brauer et al. (1998) found the concentration of $\mathrm{Ca}$ in phloem sap in a range of 10 to $100 \mu \mathrm{M}$, which is far higher than that reported in cytosol. In the pedicels of all the fruits examined, phloem had a greater $\mathrm{Ca}$ abundance than xylem (Figure 3). Therefore, Ca transport to fruit via phloem/symplast pathway cannot be ruled out, especially in fruits like apple, whose xylem dysfunction occurs very early during fruit development (Miqueloto et al., 2014; Figure 5).

The present study shows that it is a universal phenomenon among plant species that pedicel has a higher $\mathrm{Ca}$ concentration than the fruit, although the pedicel-fruit $\mathrm{Ca}$ concentration gradient (3-10 times) differs among genotypes. In previous studies in litchi, we found that Ca concentration in the pedicel was ten times higher than in the fruit pericarp, and suggested that there might be a "bottleneck effect" of Ca transport in the pedicel (Huang et al., 2006; Song et al., 2018), which results in more $\mathrm{Ca}$ accumulation in the pedicel when more $\mathrm{Ca}$ is transported toward the fruit. Thus a positive correlation between $\mathrm{Ca}$ in the pedicel and in the fruit should be found. In this study, across species/varieties as well as within Dl-SX, Ej-ZZ6, Lc-GW, and Lc-NMC, Ca concentrations in the pedicel and the fruit displayed a good positive correlation (Figure 1 and Table 4). The results suggest a generally synchronous accumulation of $\mathrm{Ca}$ in the fruit and in the pedicel. However, in the other species/varieties beyond Dl-SX, Ej-ZZ6, Lc-GW, and Lc-NMC, the correlation between calcium concentrations in the pedicel and the fruit was not significant. It is likely that the Ca accumulated in the pedicel might be remobilized to the fruit via phloem pathway, which breaks the correlation. Further studies are needed to understand the change patterns of the quantity and forms of $\mathrm{Ca}$ in the phloem of pedicel and to clarify its relation with fruit $\mathrm{Ca}$ uptake.

\section{Relations of Fruit Ca Uptake Capacity With Xylem Characters in the Pedicel}

Xylem sap influx, one of the key determinants of fruit Ca uptake capacity (Saure, 2005; Hocking et al., 2016), is determined by xylem hydraulic conductivity, which itself is a function of vessel size (Tyree and Ewers, 1991; Zach et al., 2010). In this study, neither fruit Ca uptake rate nor fruit Ca uptake activity was found to have a significant correlation with pedicel xylem anatomical characters, including xylem area, xylem coverage, vessel density, total vessel area and vessel size in the pedicel across the tested fruit species and varieties. The results indicate that these xylem characters in the pedicel are not a rate-limiting factor in $\mathrm{Ca}$ delivery to the fruit. Dye tracing showed that in most fruits xylem functionality loss occurred at the fruit-pedicel joining site as fruit matured, indicating this site might be a rate-limiting "bottleneck" in Ca transport to fruit. Indeed, Mazzeo et al. (2013) found that hydraulic resistance in the receptacle portion, that included the fruit-pedicel joint, was the highest in kiwi. Further anatomical study in relation to fruit Ca uptake capacity should focus on this site.

\section{CONCLUSION}

The following conclusions could be drawn based on our results and the above discussions. (1) fruit growth may be a dominant determinant of Ca uptake; (2) the universal pattern of Ca being higher in the pedicel than in the fruit indicates existence of a pedicel-fruit "bottleneck" effect in Ca transport across species; (3) xylem functionality loss with fruit maturation is also a universal event; (4) in the pedicel, Ca is generally more distributed in the phloem; (5) vessel morphology in the pedicel is not rate-limiting for fruit Ca uptake; (6) phloem pathway might contribute to fruit Ca uptake.

\section{AUTHOR CONTRIBUTIONS}

WS, JY, and OK performed the field experiments and lab analyses, data processing, and contributed draft writing. $\mathrm{HW}$ and $\mathrm{XH}$ contributed to the experimental design, research fund, and critical revising of the manuscript.

\section{FUNDING}

This study was supported by the National Natural Science Foundation of China (No.31372009), the "Yangfan" Project (2014YT02H013), the National Litchi and Longan Research System (CARS-33-11), and Guangdong Exotic Fruit Industry Research System (2017LM1130).

\section{SUPPLEMENTARY MATERIAL}

The Supplementary Material for this article can be found online at: https://www.frontiersin.org/articles/10.3389/fpls.2018.00575/ full\#supplementary-material

FIGURE S1 | Changes in VPD in different sampling sites. (A) Hourly VPD change in Zhajiang, where loquat fruit were collected; (B) Hourly VPD change in Guizhou, where apple and pear fruits were collected; (C) Daily VPD change in Shenzhen, where litchi and longan fruit were sampled. Bars indicate fruit development periods.

FIGURE S2 | Hourly changes in VPD in South China Agricultural University, Guangzhou. Bars indicate development periods of fruits sampled. 


\section{REFERENCES}

Bangerth, F. (1979). Calcium-related physiological disorders of plants. Annu. Rev. Phytopathol. 17, 97-122. doi: 10.1146/annurev.py.17.090179.000525

Brauer, M., Zhong, W. J., Jelitto, T., Schobert, C., Sanders, D., and Komor, E. (1998). Free calcium ion concentration in the sieve-tube sap of Ricinus communis L. seedlings. Planta 206, 103-107. doi: 10.1007/s004250050379

Choat, B., Gambetta, G. A., Shackel, K. A., and Matthews, M. A. (2009). Vascular function in grape berries across development and its relevance to apparent hydraulic isolation. Plant Physiol. 151, 1677-1687. doi: 10.1104/pp.109. 143172

Coombe, B. G., and McCarthy, M. G. (2000). Dynamics of berry growth and physiology of ripening. Aust. J. Grape Wine Res. 6, 131-135. doi: 10.1111/j.17550238.2000.tb00171.x

Dichio, B., Remorini, D., and Lang, S. (2003). Developmental changes in xylem functionality in kiwifruit fruit: implications for fruit calcium accumulation. Acta Hortic. 610, 191-195. doi: 10.17660/ActaHortic.2003.610.25

Düring, H., Lang, A., and Oggioni, F. (1987). Patterns of water flow in Riesling berries in relation to developmental changes in their xylem morphology. Vitis 26, 123-131.

Fan, Y., Yin, J., and Huang, X. (2014). The cracking-resistance, long shelf life on tree and storability of new litchi variety Lingfengnuo. Chin. J. Trop. Crops 35, 2469-2473.

Ferguson, I. B. (1980). Movement of mineral nutrients into the developing fruit of the kiwifruit (Actinidia chinensis Planch). N. Z. J. Agric. Res. 23, 349-353. doi: 10.1080/00288233.1980.10425366

Franceschi, V. R., and Nakata, P. A. (2005). Calcium oxalate in plants: formation and function. Annu. Rev. Plant Biol. 56, 41-71. doi: 10.1146/annurev.arplant. 56.032604.144106

Gilliham, M., Dayod, M., Hocking, B. J., Xu, B., Conn, S. J., and Kaiser, B. N. (2011). Calcium delivery and storage in plant leaves: exploring the link with water flow. J. Exp. Bot. 62, 2233-2250. doi: 10.1093/jxb/err111

Hanson, J. B. (1984). "The function of calcium in plant nutrition", in Advances in Plant Nutrition, eds P. B. Tinker and A. Lauchli (New York, NY: Praeger Publishers), 149-208.

Himelrick, D. G., and McDuffie, R. F. (1983). The calcium cycle: uptake and distribution in apple trees. HortScience 18, 147-151.

Ho, L. C., and White, P. J. (2005). A cellular hypothesis for the induction of blossom-end rot in tomato fruit. Ann. Bot. 95, 571-581. doi: 10.1093/aob/ mci065

Hocking, B., Tyerman, S. D., Burton, R. A., and Gilliham, M. (2016). Fruit calcium: transport and physiology. Front. Plant Sci. 29:569. doi: 10.3389/fpls.2016.00569

Huang, X. M., Wang, H. C., Li, J. G., Yuan, W. Q., Lu, J. M., Huang, H. B., et al. (2006). The presence of oxalate in the pericarp and fruit pedicel is not linked to a shortage of fruit calcium and increase in cracking incidence in litchi. J. Hortic. Sci. Biotechnol. 81, 231-237. doi: 10.1080/14620316.2006.11512055

Huang, X. M., Wang, H. C., Li, J. G., Yuan, W. Q., and Yin, J. H. (2005a). An overview of calcium's role in lychee fruit cracking. Acta Hortic. 665, 231-240. doi: 10.17660/ActaHortic.2005.665.26

Huang, X. M., Wang, H. C., Yuan, W. Q., Lu, J. M., Yin, J. H., Luo, S., et al. (2005b). Study of rapid senescence of detached litchi: role of water loss and calcium. Postharvest Biol. Technol. 36, 177-189. doi: 10.1016/j.postharvbio.2004. 12.005

Jones, H. G., Higg, K. H., and Samuelso, T. J. (1983). Calcium uptake by developing apple fruits. I. Seasonal changes in calcium content of fruit. J. Hortic. Sci. 58, 173-182. doi: 10.1080/00221589.1983.11515107

Mazzeo, M., Dichio, B., Clearwater, M. J., Montanaro, G., and Xiloyannis, C. (2013). Hydraulic resistance of developing Actinidia fruit. Ann. Bot. 112, 197-205. doi: 10.1093/aob/mct101

Miqueloto, A., do Amarante, C. V. T., Steffens, C. A., dos Santos, A., and Mitcham, E. (2014). Relationship between xylem functionality, calcium content and the incidence of bitter pit in apple fruit. Sci. Hortic. 165, 319-323. doi: 10.1016/j.scienta.2013.11.029
Montanaro, G., Dichio, B., Lang, A., Mininni, A. N., Nuzzo, V., Clearwater, M. J., et al. (2014). Internal versus external control of calcium nutrition in kiwifruit. J. Plant Nutr. Soil Sci. 177, 819-830. doi: 10.1002/jpln.201400396

Montanaro, G., Dichio, B., Lang, A., Mininni, A. N., and Xiloyannis, C. (2015). Fruit calcium accumulation coupled and uncoupled from its transpiration in kiwifruit. J. Plant Physiol. 181, 67-74. doi: 10.1016/j.jplph.2015.04.004

Montanaro, G., Dichio, B., and Xiloyannis, C. (2010). Significance of fruit transpiration on calcium nutrition in developing apricot fruit. J. Plant Nutr. Soil Sci. 173, 618-622. doi: 10.1002/jpln.200900376

Montanaro, G., Dichio, B., and Xiloyannis, C. A. (2012). Fruit transpiration in kiwifruit: environmental drivers and predictive model. AoB Plants 2012:pls036. doi: 10.1093/aobpla/pls036

Saure, M. C. (2005). Calcium translocation to fleshy fruit: its mechanism and endogenous control. Sci. Hortic. 105, 65-89. doi: 10.1016/j.scienta.2004.10.003

Shear, C. B. (1975). Calcium-related disorders of fruits and vegetables. HortScience 10, 361-365.

Song, W. P., Chen, W., Kurniadinata, O. F., Wang, H. C., and Huang, X. M. (2014). Application of electron probe to the observation of in situ calcium distribution in fruit tissues. J. Fruit Sci. 31, 730-732.

Song, W. P., Chen, W., Yi, J. W., Wang, H. C., and Huang, X. M. (2018). $\mathrm{Ca}$ distribution pattern in litchi fruit and pedicel and impact of Ca channel inhibitor, $\mathrm{La}^{3+}$. Front. Plant Sci. 8:2228. doi: 10.3389/fpls.2017.02228

Stebbins, R. L., and Dewey, D. H. (1972). Role of transpiration and phloem transport in accumulation of 45 calcium in leaves of young apple trees. J. Am. Soc. Hort. Sci. 97, 471-474.

Tonetto de Freitas, S., Mcelrone, A. J., Shackel, K. A., and Mitcham, E. J. (2014). Calcium partitioning and allocation and blossom-end rot development in tomato plants in response to whole-plant and fruit-specific abscisic acid treatments. J. Exp. Bot. 65, 235-247. doi: 10.1093/jxb/ert364

Tonetto de Freitas, S., and Mitcham, E. J. (2012). "Factors involved in fruit calcium deficiency disorders," in Horticultural Reviews, ed. J. Janick (New York, NY: John Wiley \& Sons, Inc.), 107-146. doi: 10.1002/9781118351871.ch3

Tromp, J. (1979). The intake curve for calcium into apple fruits under various environmental conditions. Commun. Soil Sci. Plant Anal. 10, 325-335. doi: 10.1080/00103627909366898

Tyree, M. T., and Ewers, F. W. (1991). The hydraulic architecture of trees and other woody pants. New Phytol. 199, 345-360. doi: 10.1111/j.1469-8137.1991. tb00035.x

Vemmos, S. N. (2005). Effects of shoot girdling on bud abscission, carbohydrate and nutrient concentrations in pistachio (Pistacia vera L.). J. Hortic. Sci. Biotechnol. 80, 529-536. doi: 10.1080/14620316.2005.11511973

White, P. J., and Broadley, M. R. (2003). Calcium in plants. Ann. Bot. 92, 487-511. doi: $10.1093 / \mathrm{aob} / \mathrm{mcg} 164$

Yang, H. Q., and Jie, Y. L. (2005). Uptake and transport of calcium in plants. J. Plant Physiol. Mol. Biol. 31, 227-234.

Zach, A., Schuldt, B., Brix, S., Horna, V., Culmsee, H., and Leuschner, C. (2010). Vessel diameter and xylem hydraulic conductivity increase with tree height in tropical rain forest trees in Sulawesi, Indonesia. Flora 205, 506-512. doi: 10.1016/j.flora.2009.12.008

Zocchi, G., and Mignani, I. (1995). Calcium physiology and metabolism in fruit trees. Acta Hortic. 383, 15-23. doi: 10.17660/ActaHortic.1995.383.2

Conflict of Interest Statement: The authors declare that the research was conducted in the absence of any commercial or financial relationships that could be construed as a potential conflict of interest.

Copyright (c) 2018 Song, Yi, Kurniadinata, Wang and Huang. This is an open-access article distributed under the terms of the Creative Commons Attribution License (CC BY). The use, distribution or reproduction in other forums is permitted, provided the original author(s) and the copyright owner are credited and that the original publication in this journal is cited, in accordance with accepted academic practice. No use, distribution or reproduction is permitted which does not comply with these terms. 